\title{
ELASTIC STRESSES IN LAYERED SNOW PAGKS*
}

\author{
By F. W. Sмiтн \\ (Department of Mechanical Engineering, Colorado State University, Fort Collins, Colorado \\ 8052 I, U.S.A.)
}

\begin{abstract}
A two-dimensional finite element computer program has been used to compute the elastic stress distribution in realistic multi-layered snow packs. Computations have been done on three-layered and five-layered snow packs intended to simulate conditions on the Lift Gully at Berthoud Pass, Colorado. Calculations have been performed to determine the effect of a layer of new snow and the effect of a weak sub-layer. Stress levels were obtained which are reasonable compared with available snow strength data.

RÉsumÉ. Efforts élastiques dans un manteau neigeux stratifié. Un programme de calculateur à éléments finis à deux dimensions a été utilisé pour calculer la distribution des contraintes élastiques dans un manteau neigeux réel à plusieurs couches. Les calculs ont été faits sur des manteaux à trois et cinq couches en vue de simuler les conditions réelles du Lift Gully au Berthoud Pass, Colorado. Les calculs ont été conduits pour déterminer l'effet d'une couche de neige fraîche et l'effet d'une couche fragile sous-jacente. Les niveaux de contrainte obtenus sont raisonnables, compte tenu des données disponibles sur les résistances mécaniques de la neige.

Zusammenfassung. Elastische Spannungen in geschichteten Schneedecken. Zur Berechnung der Verteilung elastischer Spannungen in realistischen, mehrschichtigen Schneedecken wurde ein Rechnenprogramm mit zweidimensionalen finiten Elementen benutzt. Die Durchrechnungen erstreckten sich auf Schneedecken mit drei bzw. mit fünf Schichten, um die Bedingungen auf dem Lift Gully am Berthoud Pass, Colorado, zu simulieren. Sonderrechnungen dienten der Bestimmung der Auswirkungen sowohl einer Neuschneelage wie auch einer schwachen Unterschicht. Es wurden Spannungsgrössen erhalten, die sich vernünftig mit verfügbaren Werten der Schneefestigkeit vergleichen lassen.
\end{abstract}

\section{INTRODUGTION}

The work presented in this paper is a continuation of work presented by the author (Smith and others, I97 I) in which the distribution of stresses was computed for the case of a homogeneous, single-layer avalanche snow pack. While that earlier work gave realistic values for stresses and provided some insight regarding the nature of the stress distribution in an avalanche snow pack, it did not account for the fact that most avalanche snow packs are made up of several layers of snow having dissimilar material properties. The present work attempts to alleviate this deficiency by presenting results for a three-layered snow pack which is an estimate of typical conditions which occur on the Lift Gully at Berthoud Pass, Colorado. Results are also presented for a five-layer snow pack which is based on measurements taken on an actual snow pack at Berthoud Pass.

\section{METHOD OF APPROACH}

In this analysis, a two-dimensional finite-element computer program was used which was developed by Wilson and Clough (unpublished). In applying the finite element method, the snow pack is subdivided into many small triangular elements. It is assumed that the stress and strain are constant within each element. The computer program then calculates the stress and strain for each element in the system, satisfying the equations of elasticity and the boundary conditions of the problem. Since the snow pack is divided into small triangles of arbitrarily specified size and shape, it is possible to model the complex geometries which are encountered in realistic snow packs and it is possible to accommodate variations in material properties from layer to layer.

For the snow packs analyzed in this work the following boundary conditions were assumed unless otherwise stated: The top surface of the snow pack is free of stress, the bottom layer of the snow pack is pinned to the slope, and no relative slippage between snow layers is allowed. Conditions of plane strain were also assumed.

* This paper was presented at the Fall 197 I Meeting of the American Geophysical Union, San Francisco, California. 


\section{Three-LAYERED SNOW PACK}

The three-layered snow pack which was analyzed is illustrated in Figure I, which shows an array of typical finite elements. The thickness variation and material properties of the three snow layers are estimates of typical conditions on the Lift Gully at Berthoud Pass. Each

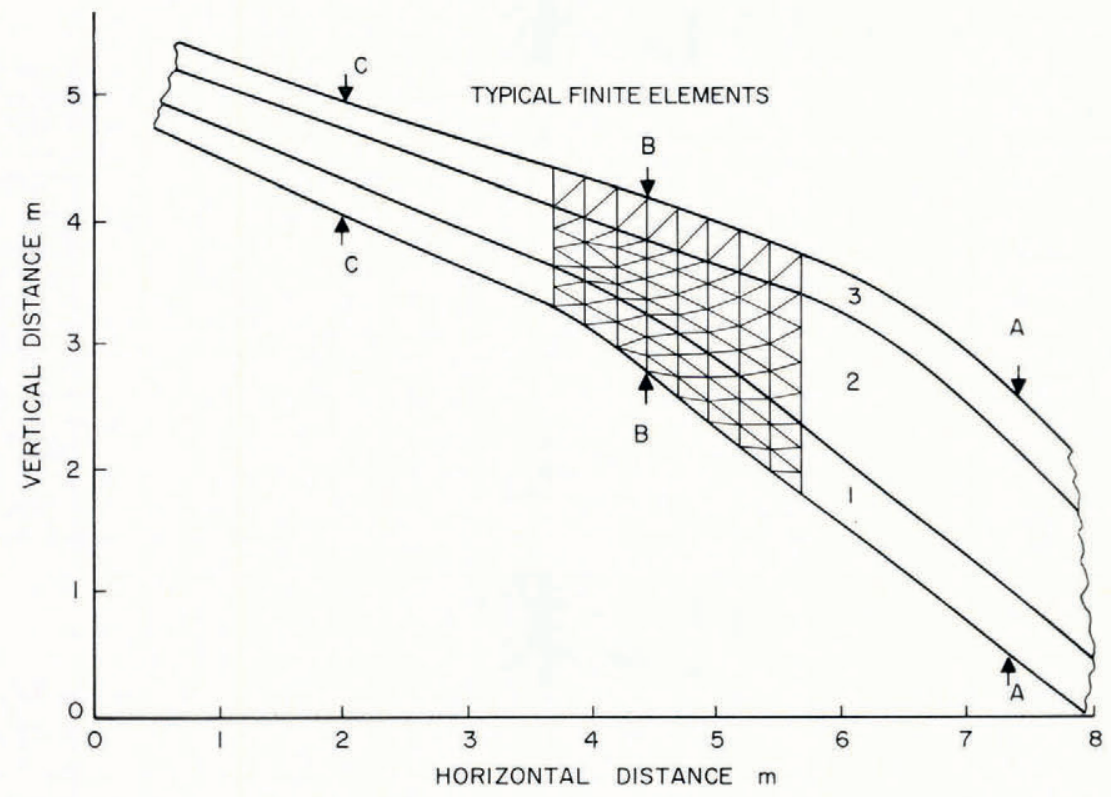

Fig. 1 . Three-layered snow pack.

snow layer was assumed to be homogeneous, but the mechanical properties were assumed to vary from layer to layer according to Table I. The Poisson's ratio was taken to be 0.2. Calculations presented by Smith and others (197I) indicated that the stresses do not vary strongly as a function of Poisson's ratio so the choice of this value is not critical.

TAble I. Mechanical properties ASSUMEd For the three LAYers

$\begin{array}{ccc}\text { Layer no. } & \begin{array}{c}\text { Density } \\ \mathrm{kg} \mathrm{m}^{-3}\end{array} & \begin{array}{c}\text { Modulus of elasticity } \\ \mathrm{GN} \mathrm{m}^{-2}\end{array} \\ \mathrm{I} & 310 & 0.2 \\ 2 & 227 & 0.2 \\ 3 & 127 & 0.2\end{array}$

Figures 2 and 3 present the results of the stress analysis. Figure 2 presents the variation of the tangential stress and the maximum shear stress with vertical height measured from the bottom of the snow pack. The results presented here are very similar in character to those presented by Smith and others (I97I). The shear stress increases smoothly to a maximum value at the bottom of the snow pack at all locations. The tangential stress (stress tangent to the slope of the hill) is primarily compressive and small in magnitude compared with the shear stresses. It is noted, as in the previous work (Smith and others, 197I), that the tangential stress becomes tensile in the top layer near the observed fracture line (point в) and remains tensile, but is of smaller magnitude at point c. Figure 3 presents the variation of the tangential stress in the top layer and the maximum shear in the bottom layer with horizontal distance. 


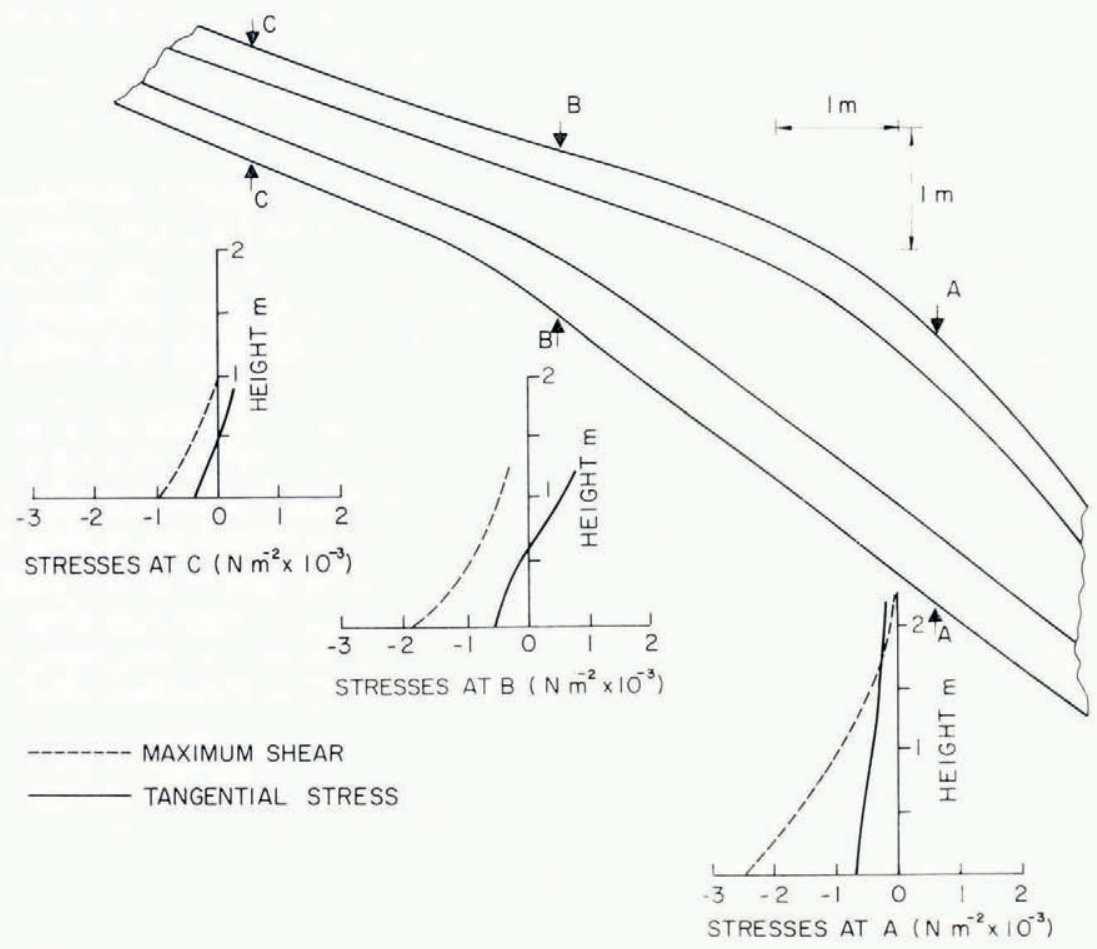

Fig. 2. Stresses in a three-layered snow pack.

For reference, the points A, B and $\mathrm{c}$ are shown on the graph. The shear stress increases to a maximum value at point A which is somewhat down slope from the observed fracture line. The shear then decreases steadily with position below point A. The tangential stress increases to a maximum tensile value at about point $\mathrm{B}$, the observed fracture line, and then becomes compressive further down the slope.

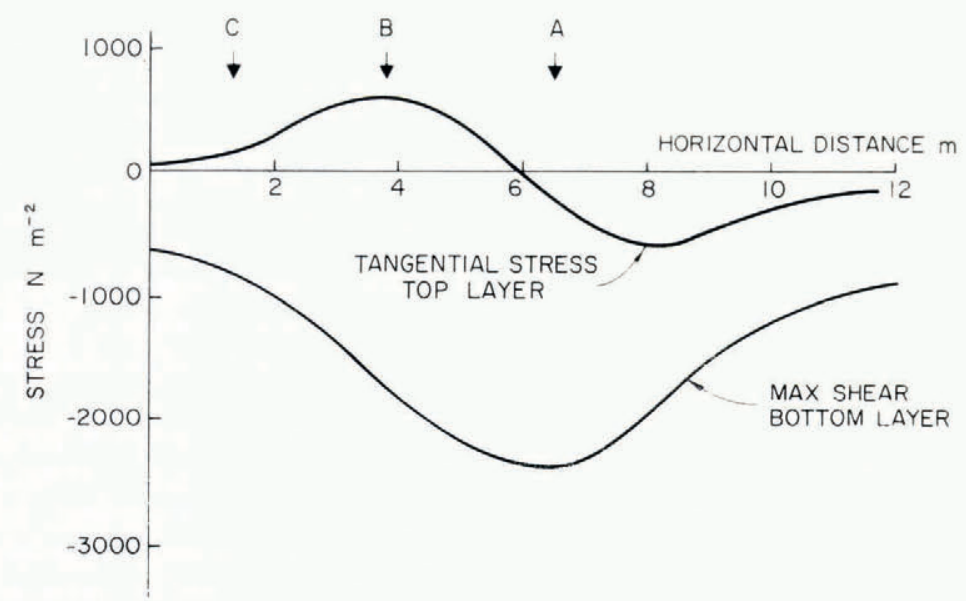

Fig. 3. Variation of stress with horizontal distance in a three-layered snow pack. 
The results presented here may be compared in part to results presented by Mellor (i 968 ). In that work stresses in the snow pack were computed to be

$$
\begin{aligned}
& \tau_{x y}=\int \rho g \sin \theta \mathrm{d} y \\
& \tau_{y y}=\int \rho g \cos \theta \mathrm{d} y
\end{aligned}
$$

where $\theta$ is the slope angle and $x$ and $y$ represent coordinates tangential and normal to the snow pack respectively. This analysis assumes plane strain conditions and it assumes that the stresses do not vary in the $x$ direction. The latter assumption drops the tangential stress from the analysis, which is not the case for the results being presented here. However, when the shear stress $\tau_{x y}$ is computed for the snow pack of Figure 2 using the above equation a favorable comparison is found.

Figure 4 gives the variation of shear strength with density for low density snows as presented by Mellor (r966). The plotted points are the maximum shear stress for each of the layers as determined from Figure 2. Figure 4 indicates that in the region of point $\mathrm{A}$, the maximum shear stress falls slightly below the lowest shear strength in the bottom layer while the maximum shear stress falls within the shear strength envelope for the middle layer. This indicates that for the geometry under consideration, a shear failure which might cause an avalanche would be more likely in the middle layer than in the bottom layer. Avalanches in which the upper layers of a snow pack shear away from the lower layers are commonly observed.

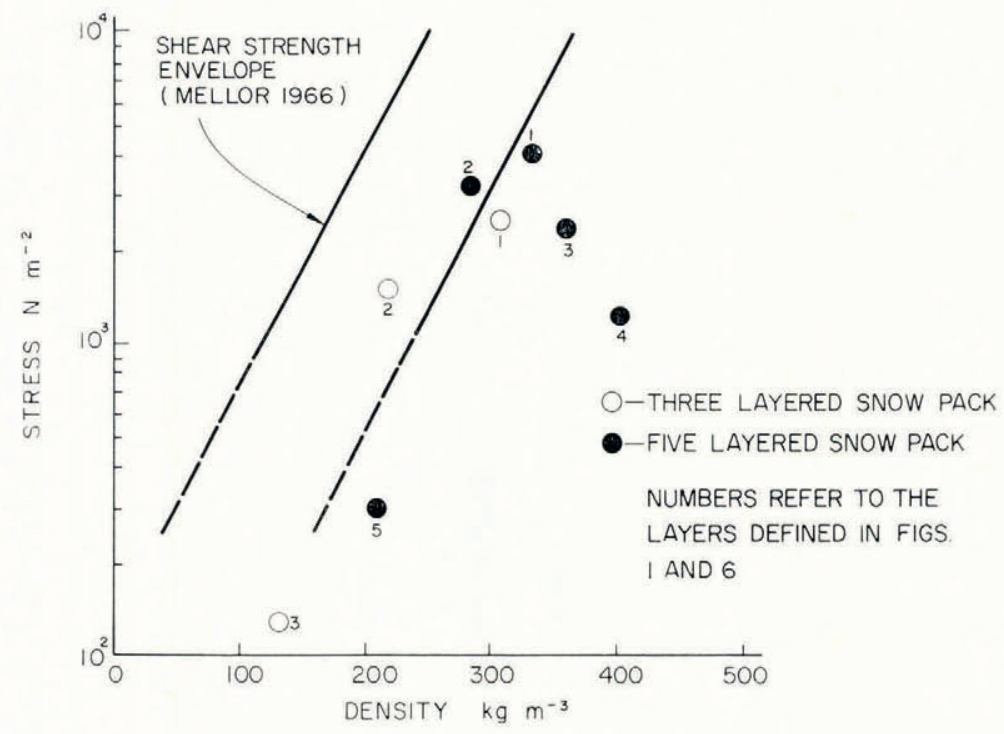

Fig. 4. Shear strength of snow compared with stresses deduced for the layers.

In considering the overall mechanism of avalanche release it would be very important to compare the probability of a shear failure in the bottom layer at point $\mathrm{A}$, where the shear is maximum, to the probability of a tensile failure in the top layer at point $\mathrm{B}$ where the tension is maximum. This comparison has not yet been done.

One of the things of interest in analyzing the stresses in avalanche snow packs is the effect of a new layer of snow on the stress distribution within the pack. Figure 5 presents the stresses found in the three-layered snow pack with the top layer removed. It is observed that the same general pattern of stresses is maintained as in the case for three layers. By comparing Figure 5 with Figure 2, the expected result is observed that the stresses increase by about $20 \%$ due to the addition of the third snow layer. 


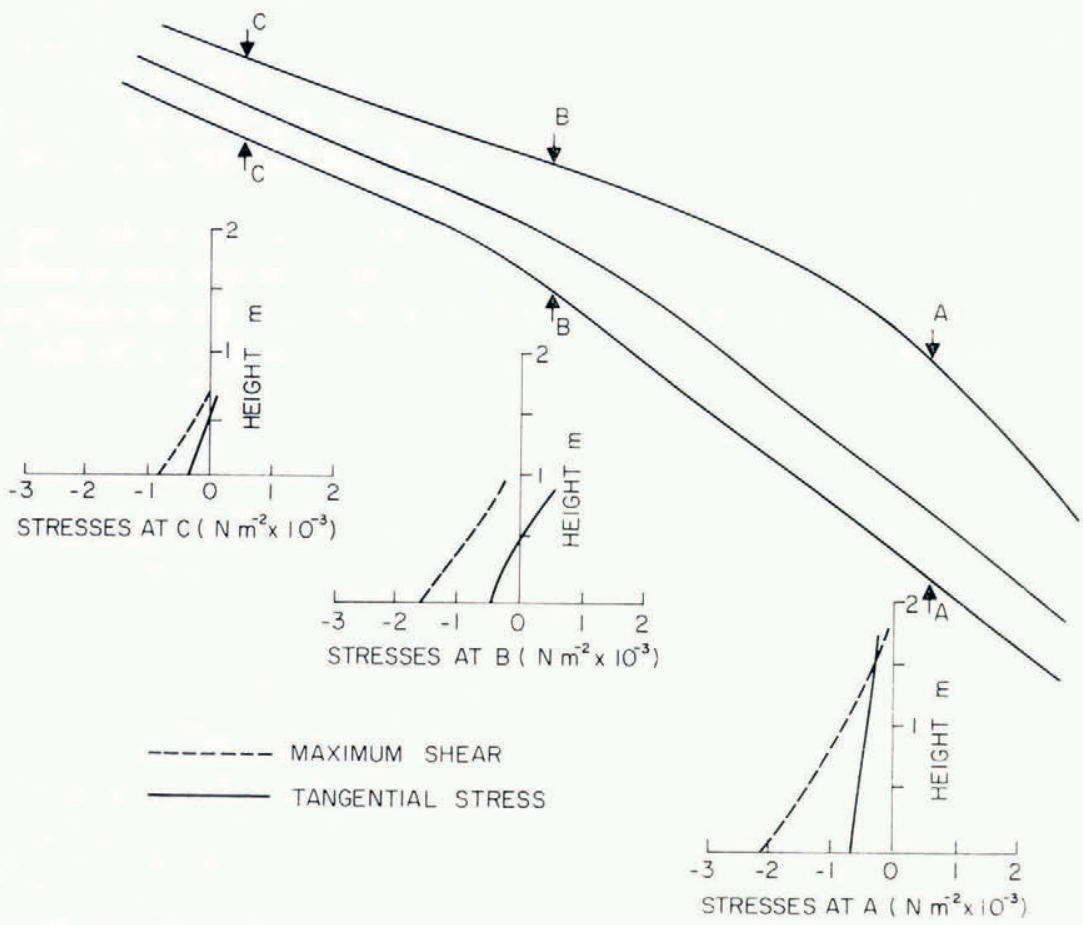

Fig. 5. Stresses in a two-layered snow pack.

\section{FIVE-LAYERED SNOW PACK}

After completion of the calculations on the three-layered snow pack, an attempt was made to model a snow pack based on actual measurements taken at Berthoud Pass. Figure 6 presents the geometry which was considered for this case. The properties for the snow in each layer are presented in Table II.

TAble II. Mechanical properties Assumed For the five LAYers

\section{Layer no.}

I
2
3
4
5

$$
\begin{gathered}
\begin{array}{c}
\text { Density } \\
\mathrm{kg} \mathrm{m}^{-3}
\end{array} \\
330 \\
290 \\
360 \\
400 \\
210
\end{gathered}
$$

Modulus of elasticity

$\mathrm{GN} \mathrm{m}^{-2}$

$$
\begin{aligned}
& 0.2 \\
& 0.2 \\
& 0.2 \\
& 0.2 \\
& 0.2
\end{aligned}
$$

In each layer the Poisson's ratio again was taken to be o.2. Figure 6 presents the stresses which resulted from an analysis of the five-layered snow pack. The same general variation of stresses is noted in the five-layered pack as were noted in the three-layered snow pack. The shear stresses in the bottom layer are somewhat larger than for the three-layered snow pack. A comparison of the shear stresses in Figure 6 with the shear strength for each layer is given in Figure 4 and indicates that layer 2 is the only one for which the shear stress falls within the shear failure envelope. Thus a shearing failure may be possible in this layer leaving the bottom layer intact. 
The tensile stresses in the top layer are somewhat smaller for this case than for the threelayered snow pack. In addition the variation with horizontal distance is somewhat different as is indicated by Figure 7. As before, point в is the location of the observed fracture line. In this case the tensile stress does not peak at that point, but reaches a maximum at a point above point c. This result tends to argue against the concept that tensile stresses in the top layer are the controlling mechanism of avalanche release.

A study of a more complete profile of the five-layered snow pack than that given in Figure 6 indicates that the top layer in the region above point $\mathrm{c}$ is concave as is the top layer between B and c. It is noted that the tangential stress is tensile just above B and just above $\mathrm{G}$. A study of Figures 2 and 5 indicates concavity of the top layer just above point $\mathrm{B}$. In both of

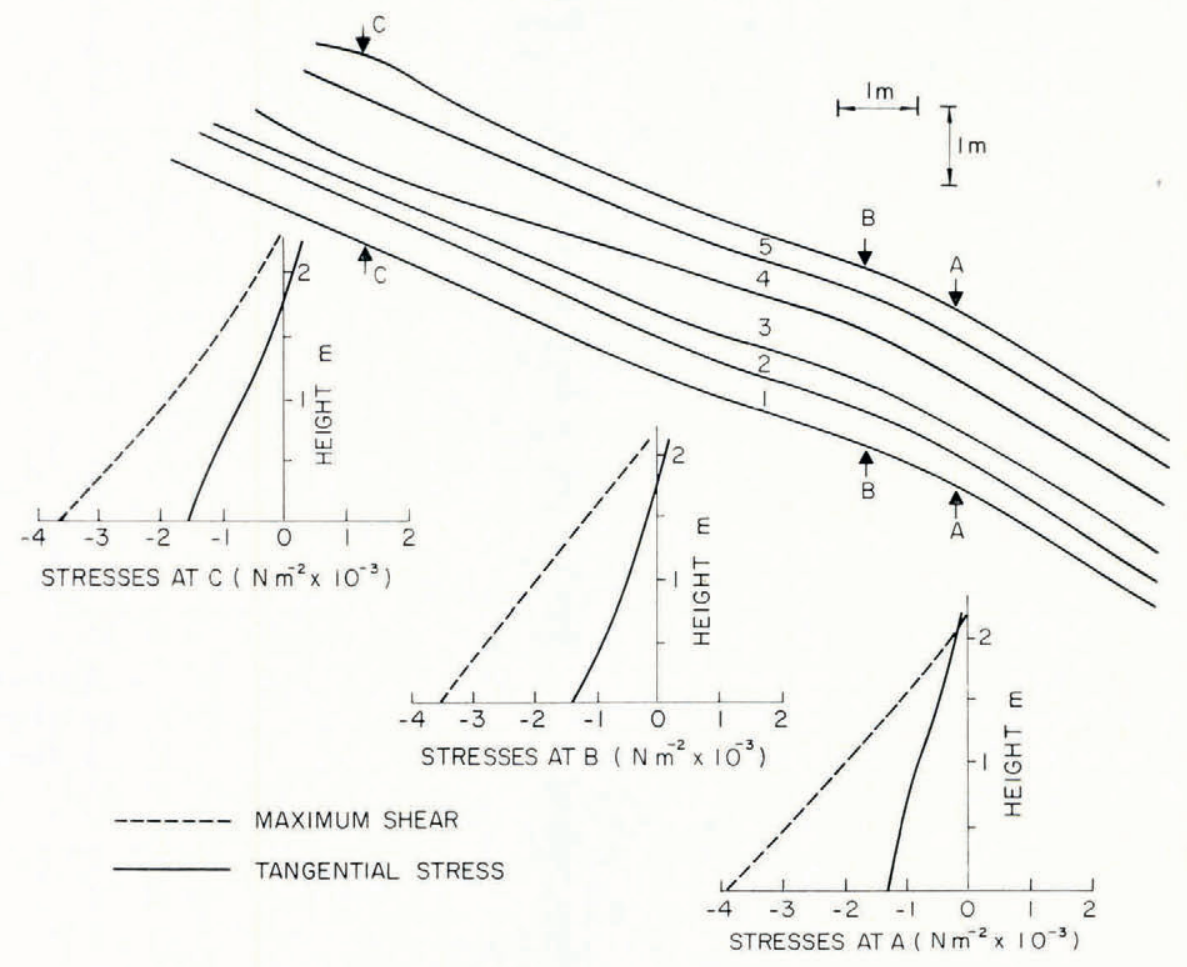

Fig. 6. Stresses in a five-layered snow pack.

these cases, the tangential stress is also tensile. This leads one to speculate that the lower end of a region of concavity in the top layer is subjected to tangential stresses which are tensile.

One of the mechanisms of avalanche release which has been considered is the collapse of a layer of depth hoar near the bottom of the snow pack. This condition was simulated for the five-layered snow pack by prescribing Young's modulus in the bottom layer to be one-tenth of that for the rest of the snow pack, allowing large deformations in that layer. In addition the top end of the snow pack was fixed throughout the full depth to simulate pinning of the snow pack by trees or rocks. The resulting stresses are presented in Figures 8 and 9 using the usual format. The shear stresses have about the same variation and magnitude as shown in Figure 6. The tangential stresses, however, show a much larger tensile magnitude all along the top layer, approaching a value near I $\mathrm{I}$ ooo $\mathrm{N} \mathrm{m}^{-2}$ at the location where the snow pack is 


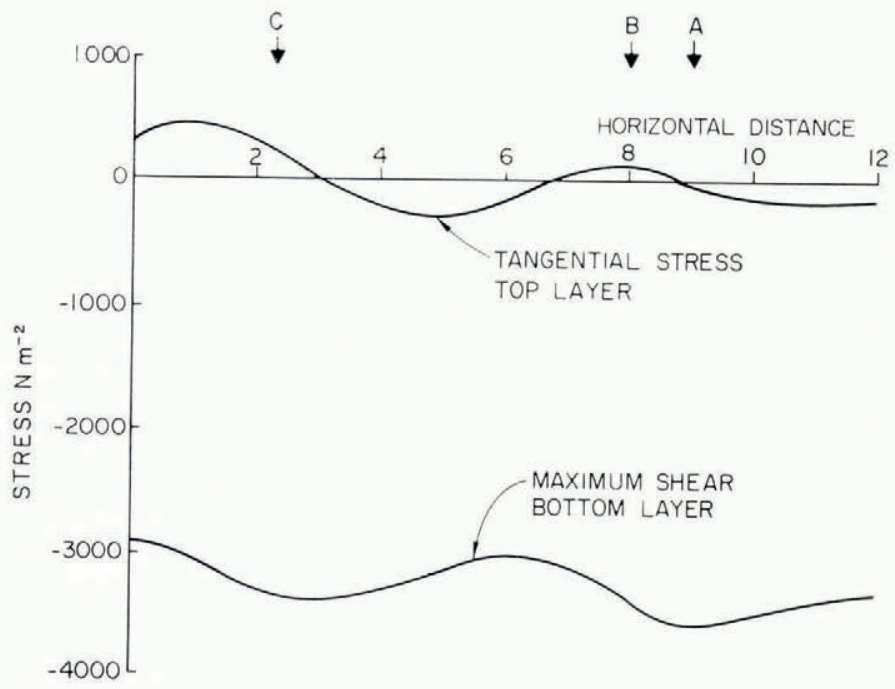

Fig. 7. Variation of stress with horizontal distance in a five-layered snow pack.

pinned far above point c. This value is reasonable when compared with the expected tensile strength of the top layer of the snow pack. The simulation of this problem indicates that avalanche release associated with collapse of a weak sublayer is probably due to a tensile failure in the upper layer and that the failure probably occurs near obstacles which pin the snow pack to the slope.

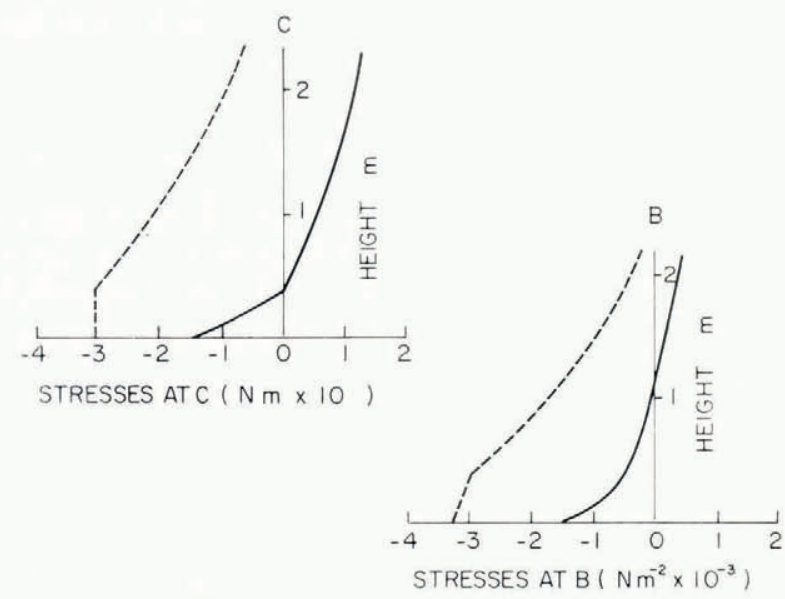

MAXIMUM SHEAR

TANGENTIAL STRESS

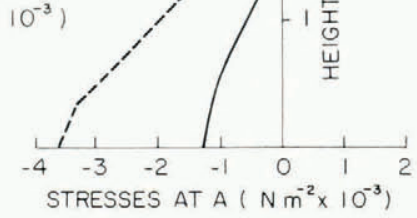

Fig. 8. Stresses in a five-layered snow pack with a weak sub-layer. 


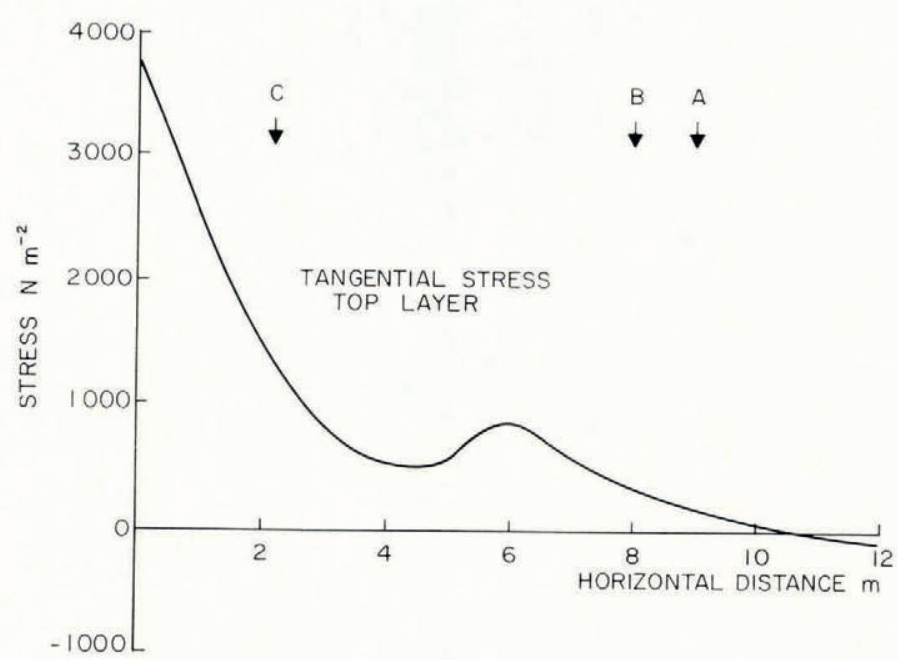

Fig. 9. Variation of stress in a five-layered snow pack with a weak sub-layer.

\section{Conclusion}

Elastic stresses were computed for realistic three-layered and five-layered snow packs demonstrating the approximate distributions and stress magnitudes which may be expected to occur. The numerical model gave results which indicate the possibility of a shearing failure in other than the bottom layer, a phenomenon which is commonly observed in actual avalanches. The numerical model was also used to predict the effect of a weak sub-layer. It was found to give unrealistically high tensile stresses in the top layer for this case, but tends to indicate that avalanche release by this process is probably tension controlled.

While the analysis presented here does not account for the non-linear and time-varying properties of snow, it does appear to give results for stresses which predict behavior that is reasonably consistent with field experience.

\section{Acknowledgement}

The author gratefully acknowledges the financial support of this work by the Rocky Mountain Forest and Range Experiment Station, U.S. Department of Agriculture Forest Service, Fort Collins, Colorado. Also the author is indebted to R. A. Sommerfeld of that organization for his encouragement and many helpful discussions.

MS. received 20 January 1972 and in revised form II April 1972

\section{REFERENCES}

Mellor, M. 1966. Snow mechanics. Applied Mechanics Reviews, Vol. 19, No. 5, p. 379-89.

Mellor, M. I968. Avalanches. U.S. Cold Regions Research and Engineering Laboratory. Cold regions science and engineering. Hanover, N.H., Pt. III, Sect. A3d.

Smith, F. W., and others. I 97 I. Finite-element stress analysis of avalanche snowpacks, by F. W. Smith, R. A. Sommerfeld and R. O. Bailey. Journal of Glaciology, Vol. io, No. 6o, p. 401-05.

Wilson, E. L., and Clough, R. W. Unpublished. Finite element analysis of two-dimensional structures. [Ph.D. thesis, University of California, Berkeley, r 963.$]$ 